traditional drugs. The study also showed an improvement in attitude to medications in patients taking olanzapine.

The reasons for this change in attitude, however, remain unclear. A clear link between the greater tolerability of atypical medications and better compliance rates has yet to be shown, but this study suggests that olanzapine and the newer atypicals represent an advance in the drug treatment of schizophrenia and one that may lead to greater patient satisfaction and, therefore, compliance.

\section{References}

BARNES, T. R. E. (1989) A rating scale for drug-induced akathisia. British Journal of Psychiatry, 154, 672-676.

\section{BEASLEY, C., SANGER, T., SATTERLEE,}

W., et al (1996a) Results of a doubleblind fixed-dose olanzapine trial. Psychopharmacology, 124, 159-167.

-,TOLLEFSON, G., TRAN, P., et al (1996b) Olanzapine versus haloperidol and placebo: acute phase results of North American olanzapine trial. Neuropsychopharmacology, 14, $111-124$
- HAMILTON, S., CRAWFORD, A et al (1997) Olanzapine versus haloperidol: acute phase results of the international double-blind olanzapine trial. European Neuropsychopharmacology, 7 , 125-137.

GUY,W. (1976) ECDEU Assessment Manual for Psychophamarcology. Revised DHEW Pub (ADM). Rockville, MD: National Institute of Mental Health
KANE, J. (1989) The current status of neuroleptics. Journal of Clinical Psychiatry, 50, 322-328.

KANE, J., HONINGFIELD, G., SINGER, J., et al (1988) Clozapine in treatment resistant schizophrenia: a double-blind comparison with chlorpromazine. Archives of General Psychiatry, 45, 789-796.

OLIVER, J. (1991) The social care directive: development of a quality of life profile for use in community services for the mentally ill. Social Work and Social Sciences Review, $\mathbf{3}$, 5-45.

TOLLEFSON, G., BEASLEY, C., TRAN, P., et al (1997) Olanzapine versus haloperidol in the treatment of schizophrenia, schizoaffective and schizophreniform disorders: results of an international collaborative trial. American Journal of Psychiatry, 154 466-474.

WEIDEN, P. (1991) Neuroleptic noncompliance in schizophrenia. In: Advances in Neuropsychiatry and Psychopharmacology: Schizophrenia Research (eds C. Tamminga \& S. Schultz), pp. 285-299. NewYork: Raven Press.

OVERALL, J. \& GORHAM, D. (1962) The Brief Psychiatric Rating Scale. Psychological Reports, 10,799-812.

SIMPSON, G. \& ANGUS, J. (1970) A

Rating Scale for Extrapyramidal Symptoms. Acta Psychologica Scandinavica, 212, 511-519.

James Stallard Specialist Registrar, Brent, Kensington, Chelsea and Westminster Mental Health NHS Trust, *Eileen Joyce Reader in General Psychiatry, Imperial College School of Medicine, Charing Cross Campus, St Dunstan's Road, LondonW6 8RP

\title{
Audit of in-patient prescription and administration records on acute psychogeriatric wards in a teaching hospital
}

\section{AIMS AND METHOD}

An audit of in-patient prescription and administration records on acute psychogeriatric wards in a teaching hospital measured the extent of conformity to NHS trust drug policy and improvements following specific interventions. The audit also measured doctors' knowledge of the trust drug policy. Prescription cards of all patients present on the wards were re-audited after 12 months.

\section{RESULTS}

The audit identified important shortcomings in prescription writing, recording and policy awareness. A targeted series of interventions resulted in significant improvements in some of these areas.

\section{CLINICAL IMPLICATIONS}

Continuous evaluation and feedback via audit can reduce omissions in prescription writing and recording.
The most common intervention performed by physicians is the writing of a prescription. All elements in the complex process of prescribing and administering drugs are susceptible to error (Ferner \& Upton, 1999). Bates et al (1995) reported 6.5 adverse drug events per 100 patients admitted to a Boston hospital, over a quarter of which were preventable. Drug errors are an important cause of morbidity, accounting for one-fifth of the deaths due to adverse drug events, and are therefore becoming an increasingly common subject for litigation (Ferner, 1995).

Department of Health guidelines advise that legal responsibility for prescribing lies with the doctor who signs the prescription and the British National Formulary (BNF; British Medical Association \& Royal Pharmaceutical
Society of Great Britain, 1999) has explicit guidance on prescription writing.

An audit into the effects of introducing accessible hospital prescribing guidelines for opioid analgesia demonstrated an improvement in prescribing practice (Humphries et al, 1997). Similarly Hollingsworth and Wilson (1997) in a primary care study showed that good compliance with standards is achievable.

\section{Aims}

(a) To measure the extent to which information recorded on in-patient prescription cards conforms to South Birmingham Mental Health NHS Trust regulations (1998) 
for the prescribing, handling, custody and administration of drugs. The standards are based on the Medicines Act 1968, The Misuse of Drugs Act 1971, Duthie Report

original papers

1998, UKCC Advisory Paper on Administration of Medicines 1992 and also conforms to the section in the BNF on prescription writing.

(b) To assess the knowledge of medical staff within the older adults directorate of the trust's drug policy.

(c) To improve prescribing, recording and staff knowledge via a targeted series of interventions.

\section{The study}

An audit tool was designed to ascertain whether each of the standards, as outlined in the results tables, were met on each prescription card. Questions marked were areas not specified in the standard but considered to be ideal by the authors (Tables 1-3). Prescription cards of all the patients present on the three acute psychogeriatric wards at the Queen Elizabeth Psychiatric Hospital, Birmingham, as of midnight on 10 January 1999, were examined. Each card was examined by at least two members of the multi-disciplinary audit team. Cards had to conform throughout to meet the standard. Questionnaires were handed to medical staff to ascertain whether they had been made aware of the trust's drug policy, had read it and knew where to locate it.

Following the initial audit, measures were introduced to target prescription-writing skills. The results were presented to nursing, medical and management groups. A discussion took place during the in-house medical staff teaching programme related to the role of the pharmacy department in monitoring prescription and writing.

\section{Table 1. Patient identification and Mental Health Act (MHA) details}

\begin{tabular}{|c|c|c|c|}
\hline Patient identification details & $\begin{array}{l}\text { Percentage meeting } \\
\text { standards in } 1999 \\
\quad(n=58)\end{array}$ & $\begin{array}{l}\text { Percentage meeting } \\
\text { standards in } 2000 \\
\quad(n=52)\end{array}$ & $\begin{array}{c}\text { Test of } \\
\text { proportions: } \\
P \text { value (two-tailed) }\end{array}$ \\
\hline 1. Patient's name clearly identified & $100 \%$ & $100 \%$ & \\
\hline 2. Drug allergy section completed & $14 \%$ & $52 \%$ & 0.001 \\
\hline 3a. Record of whether Section 58 is required ${ }^{1}$ & $28 \%$ & $83 \%$ & 0.001 \\
\hline $\begin{array}{l}\text { Cards meeting all patient identification and } \\
\text { MHA standards }\end{array}$ & 3 not including $3 b$ & 50 including $3 b$ & 0.001 \\
\hline
\end{tabular}

Table 2. Regular prescription medication details

\begin{tabular}{lccc}
\hline Regular prescription medication details & $\begin{array}{c}\text { Percentage meeting } \\
\text { standards in 1999 } \\
(n=57)\end{array}$ & $\begin{array}{c}\text { Percentage meeting } \\
\text { standards in 2000 } \\
(n=52)\end{array}$ & $\begin{array}{c}\text { Test of } \\
\text { proportions: } \\
P \text { value (two-tailed) }\end{array}$ \\
\hline 1. Approved name used & 79 & 81 & 0.682 \\
2. Block capitals used & 20 & 48 & 0.001 \\
3. Dose entered next to time & 97 & 94 & 0.889 \\
4. Route stated (as per code on card) & 0 & 11 & 0.001 \\
4b. No more than one route stated? & 98 & 96 & 0.497 \\
5. Drug start date stated & 90 & 87 & 0.834 \\
6. Drug stop date stated & 42 & 53 & 0.226 \\
7. Signed & 98 & 100 & 0.624 \\
\hline 1. Area that is not standard but is considered to be ideal. & \multicolumn{3}{c}{} \\
\hline
\end{tabular}

\section{Table 3. Details specific to pro re nata (PRN) medication}

Details specific to PRN medication

\section{Dose stated}

2. Frequency of dose stated

3a. Number of doses stated

3b. Not more than 12 doses stated

3c. Stated number of doses not exceeded
Percentage meeting

standards in 1999
Percentage meeting standards in 2000

$93 \%(42 / 45)$
$67 \%(30 / 45)$
$52 \%(23 / 44)$
$96 \%(22 / 23)$
$100 \%(23 / 23)$

\begin{tabular}{crc}
$94 \%(47 / 50)$ & $93 \%(42 / 45)$ & 0.741 \\
$62 \%(31 / 50)$ & $67 \%(30 / 45)$ & 0.638 \\
$16 \%(8 / 50)$ & $52 \%(23 / 44)$ & 0.001 \\
$87 \%(7 / 8)$ & $96 \%(22 / 23)$ & 0.418 \\
$87 \%(7 / 8)$ & $100 \%(23 / 23)$ & 0.085 \\
\hline
\end{tabular}

Test of proportions: $P$ value (two-tailed)

1. Area that is not standard but is considered to be ideal. 
Following this, a draft protocol for the role of pharmacy in ward rounds was constructed and subsequently used by the senior pharmacist. This protocol particularly includes checking that prescriptions are written according to the standards and monitoring the review of when required (pro re nata; PRN) medications.

Following these interventions the prescription cards of all patients present on the same three wards as of midnight on 13 January 2000 were evaluated by the same criteria.

\section{Findings}

In the first phase of the audit cycle 58 prescription cards were reviewed, and 52 in the second phase. No cards met all the standards in the first phase of the audit but in the second phase one card (2\%) met all the standards $(P=0.289)$. Table 1 indicates that patient identification and Mental Health Act (MHA) details were recorded correctly in $2 / 58(3 \%)$ cards in phase 1 and in $26 / 52(50 \%)$ cards in phase $2(P=0.001)$.

In phase 1 none of the prescription cards met all the regular medication prescription details' standards but in phase $210 \%(5 / 52)$ met these standards ( $P=0.001)$. Details of individual items are shown in Table 2 . In relation to the standard specific to PRN medication, in phase $16 \%$ of cards (3/50) met all. In phase $238 \%(17 / 45)$ met these standards $(P=0.001)$. Details of individual items are shown in Table 3. Drug administration records were complete in $51 \%(29 / 57)$ of cards in phase 1 and in $61 \%$ (30/49) of cards in phase $2(P=0.285)$.

In the first phase none of the three wards could locate a copy of the drug policy when asked, but all could at the re-audit. The majority of doctors knew that a drug policy was in place (8/10 at first audit, 5/6 at re-audit). There had been an improvement in the number of doctors who had read the drug policy at the second phase (2/10 at first audit, 4/6 at re-audit). In the first audit $7 / 10$ said that they knew where to find a copy of the drug policy, whereas $3 / 6$ did in the re-audit.

\section{Discussion}

This audit demonstrated some statistically significant improvements in prescribing practice. Pharmacists can have an important role in maintaining the quality of prescribing. Continuous evaluation and feedback have been shown to improve prescription writing (Shaughnessy \& D'Amico, 1994) and generally resident doctors are amenable to receiving such information (Anastasio \& Sigmon, 1990). There was a non-significant improvement in the completion of administration records, but 39\% remained incomplete in phase 2 . This remains a cause for concern because potentially it could lead to drugs being given twice. It is unclear why this shortcoming persisted and more specific interventions directed at nursing staff may be indicated. Pharmacists, prescribers and nurses must institute safeguards in their practice to reduce the incidence of medication omissions.

Little emphasis is placed on prescription writing in medical training (Walson et al, 1981). Trainees rotate 6 monthly, allowing insufficient time to become fully familiar with drug policies, although thorough induction programmes can help to offset these difficulties (Humphries et al, 1997). Drug policies need to be easily available and pointed out to new staff. Trainee involvement in audit is a method of raising awareness and encouraging critical evaluation of prescribing practice.

The NHS trusts should review their prescription cards to ensure that they are user friendly. Sufficient space must be provided to record relevant information, thereby facilitating compliance with standards. Approved codes for drug route, for example, need to be consistent between the standards and the key on the drug card.

There were certain limitations to this study. No attempts were made to grade the severity of the errors. Letters were sent to wards and doctors, informing them about the re-audit as a matter of courtesy. Raising awareness was a valuable part of the intervention because knowledge that practice is being observed improves performance (Shaughnessy \& D'Amico, 1994). The 110 prescription cards represented the work of a small number of doctors, not all of whom participated in both phases. Despite these limitations, audit appears to have been a valuable tool for monitoring compliance to prescribing and administration standards and for encouraging continued improvement in practice.

\section{Acknowledgements}

We would like to acknowledge Staff Nurse Janet Lewis who was part of the re-audit team, Professor Femi Oyebode for his comments and the staff at South Birmingham Mental Health Trust Mental Health Services for Older Adults for their help and cooperation.

\section{References}

ANASTASIO, G. D. \& SIGMON, J. L. (1990) Prescription writing errors. Journal of Family Practice, 30, 108.

BATES, D.W., CULLEN, D. J., LAIRD, N., et al (1995) Incidence of adverse drug events and potential adverse drug events. Implications for prevention. Journal of the American Medical Association, 274, 29-34.

BRITISH MEDICAL ASSOCIATION \& ROYAL PHARMACEUTICAL SOCIETY OF GREAT BRITAIN (1999) British National Formulary. London: BMA Books and Royal Pharmaceutical Society of Great Britain.

FERNER, R. E. (1995) Is there a cure for drug errors? BMJ, 311, 463-464.

- \& UPTON, D. (1999) Errors in prescribing, supplying and giving medicines. Prescribers' Journal, 39, 51-58.

HOLLINGSWORTH, R. \& WILSON, A. (1997) General practice prescriptions: do they conform to British National Formulary guidelines? Health Trends, 29, $13-14$.

HUMPHRIES, C. A., COUNSELL, D. J., PEDIANI, R. C., et al (1997) Audit of opioid prescribing: the effect of hospital guidelines. Anaesthesia, $\mathbf{5 2}$, 745-759.

SHAUGHNESSY, A. F. \& D'AMICO, F. (1994) Long term experience with a program to improve prescription writing skills. Family Medicine, 26, 168-171.

WALSON, P. D., MARTIN, R., ENDOW, E., et al (1981) Prescription writing in a pediatric clinic. Pediatric Pharmacology, 1, 239-244.

*Oludemilade Onalaja Specialist Registrar, West Midlands Rotational Training Scheme, South Birmingham Mental Health NHS Trust, Queen Elizabeth Psychiatric Hospital (For correspondence: Coventry Healthcare NHS Trust, The Caludon Centre, Clifford Bridge Road, Walsgrave, Coventry CV2 2TE, Ruth Saffrey Clinical Audit Officer, Mental Health Services for Older Adults, Elaine Jones Senior Pharmacist, Peter Bentham Consultant in Old Age Psychiatry, South Birmingham Mental Health NHS Trust and Honorary Clinical Senior Lecturer, University of Birmingham original papers 